JIME (Journal of Industrial and Manufacture Engineering), 5(1) Mei 2021

ISSN 2549-6328 (Print) ISSN2549-6336 (Online) DOI : 10.31289/jime.v5i1.4138

\title{
JIME
}

(Journal of Industrial and Manufacture Engineering)

Available online http://ojs.uma.ac.id/index.php/iime

\section{Analisis Human Reliability Assessment (HRA) dengan Metode HEART dan SPAR-H (Studi Kasus PT.X)}

\section{Human Reliability Assessment (HRA) Analysis with HEART and SPAR-H Methods (Case Study PT.X)}

\author{
Tita Dwi Riyanti*1), Willy Tambunan²) dan Yudi Sukmono ${ }^{3)}$ \\ Program Studi Teknik Industri, Fakultas Teknik. Universitas Mulawarman, Indonesia
}

Diterima: Agustus 2020; Disetujui: Mei 2021; Dipublikasi: Mei 2021;

*Coresponding author: rivantita@gmail.com

\section{Abstrak}

PT. X merupakan perusahaan yang bergerak dibidang kontruksi jalan dan jembatan. Penelitian ini dilakukan pada proyek pembuatan drainase, dengan 5 tahap yaitu persiapan, pemotongan, perakitan, pengecoran dan pemasangan. Terdapat beberapa kemungkinan kecelakaan kerja yang disebabkan oleh human error, dengan penerapan Human Reliability Assessment yang merupakan suatu cara analisis kegagalan dari manusia untuk penilaian resiko dan penyebab resiko diharapkan mampu mengurangi tingkat kecelakaan kerja yang ada. Metode yang digunakan yaitu metode HEART (Human Error Assessment) dan SPAR-H (Standarized Plant Analysis Risk Human Reliability Assesment). Pada penelitian ini juga menggunakan Hierarchical Task Analysis dan Fault Tree Analysis yang berguna untuk membantu identifikasi kemungkinan-kemungkinan kecelakaan kerja serta untuk mengetahui nilai kecelakaan kerja terbesar dari masing-masing sub pekerjaan, nilai persentase HEP terbesar diperoleh dari hasil metode HEART yaitu 5,39\% untuk tahap persiapan, $2,78 \%$ pada tahap pemotongan $1,88 \%$ pada tahap perakitan 5,52\% pada tahap pengecoran dan 16,89\% pada tahap pemasangan, sedangkan hasil persentase HEP dengan metode SPAR-H sebesar 4,26\% untuk tahap persiapan, 1,06\% pada tahap pemotongan, $1,67 \%$ pada tahap perakitan, 5,31\% pada tahap pengecoran dan $16,76 \%$ pada tahap pemasangan, nilai tersebut kemudian diberikan beberapa rekomendasi sesuai dengan hasil dari kuesioner yang didapatkan seperti memberikan cukup waktu istirahat untuk pekerja agar mengurangi tingkat stress pekerja dan rekomendasi lainnya.

Kata Kunci: Human Error, Human Reliability Assessment, Drainase, HEART, SPAR-H

Abstract

PT. $X$ is a company engaged in construction of roads and bridges. This research was conducted on the project in drainage construction, with 5 stages: preparation, cutting, assembly, casting and installation. There are several possible work accidents caused by human error, Human Reliability Assessment application which is a way of human failure analysis for risk assessment and risk exposure to reduce the accident rate there. This research used the HEART (Human Error Assessment) method and the SPAR-H (Plant standarized Human Reliability Analysis Risk Assessment) method, also used Hierarchical Task Analysis and Fault Tree Analysis to identify the possibilities of workplace accidents and also to investigate workplace accidents greatest value of each sub job. Assessment carried out by an expert with the existing questionnaire so that the largest percentage value obtained from the HEP HEART method that is 5,39\% for the preparatory phase, 2,78\% at the cutting stage, 1,88\% at the assembly stage, 5,52\% at the casting stage and 16,89\% during the installation phase, while the percentage of HEP with SPAR-H method is 4,26\% for the preparatory phase, $1,06 \%$ at the cutting stage, 1,677\% at the assembly stage, 5,31\% at the casting stage and 16,76\% during the installation phase, the whole value then given a number of recommendations in accordance with the result of the questionnaire to provide sufficient time off for workers to reduce stress levels of workers and other recommendations.

Keywords: Human Error, Human Reliability Assessment, Drainase, HEART, SPAR-H

How to Cite: Riyanti, Tita Dwi, Willy Tambunan dan Yudi Sukmono (2021). Analisis Human Reliability Assessment (HRA) dengan Metode HEART dan SPAR-H (Studi Kasus PT.X). JIME (Journal of Industrial and Manufacture Engineering). 5(1) : 41-48 
Tita Dwi Riyanti, Willy Tambunan dan Yudi Sukmono. Analisis Human Reliability Assessment (HRA) dengan Metode HEART dan SPAR-H (Studi Kasus PT.X).

\section{PENDAHULUAN}

Kesehatan adalah faktor yang sangat penting bagi produktivitas dan peningkatan produktivitas mengalami gangguan kesehatan akan menurun kemampuan kerja nya dalam bekerja fisik maupun dalam berfikir. Kesehatan pekerja menjadi sangat penting ketika berpengaruh terhadap keamanan pekerja dikarenakan kecelakaan kerja tidak hanya menimbulkan kerugian dalam hal korban jiwa maupun materi, tetapi juga dapat menganggu proses produksi yang kemudian merusak lingkungan hingga merugikan masyarakat luas, sehingga kesehatan dan keselamatan kerja merupakan satu upaya pelindungan yang diajukan kepada semua potensi yang dapat menimbulkan bahaya hal tersebut bertujuan agar seluruh sumber produksi serta pekerja selalu dalam keadaan sehat dan selamat selama melaksanakan pekerjaan (Suma'mur, 2009).

Human Reliability Assessment merupakan suatu cara analisis kegagalan dari manusia untuk penilaian resiko dan penyebab resiko. Dalam perusahaan, banyak sekali terdapat faktor kecelakaan kerja yang disebabkan oleh kegagalan atau kesalahan dari pekerja itu sendiri. Penerapan HRA pada penelitian ini dilakukan di anak perusahaan PT.X, dimana aktivitas yang diamati yaitu pembuatan drainase yang pada umumnya proyek ini masih banyak menggunakan tenaga manusia, sehingga perhatian terhadap pekerja sangat diperlukan agar tidak terjadi kecelakaan kerja akibat human error.

Kecelakaan-kecelakaan kerja yang terjadi seperti luka pada saat pemotongan dikarenakan pekerja kurang fokus pada saat melakukan pekerjaan, selain itu salah satu kecelakaan yang terjadi yaitu patah tulang yang diakibatkan pekerja terlalu lelah pada saat menyelesaikan pekerjaan. Oleh karena itu, penggunaan HEART dan SPAR-H yang merupakan kedua metode jenis kuantifikasi berguna untuk mengetahui nilai human error probability. Metode Human Error Assesment (HEART) merupakan suatu metode yang bertujuan untuk mengetahui nilai faktor-faktor terbesar apa yang menjadi penyebab sebuah kegagalan yang disebabkan oleh manusia atau human error, menurut Bell dan Holroyd (2009) metode ini memiliki kelebihan yaitu memiliki domain yang luas selama keandalan manusia dianggap penting, metode ini telah berhasil diterapkan di banyak industri termasuk nuklir, kimia, penerbangan, kereta api dan medis. Selain itu, metode Standarized Plant Analysis Risk Human Reliability Assesment (SPAR-H) yang berfungsi membahas mengenai potensi kecelakaan kerja melalui breakdown aktivitas, metode ini memiliki keunggulan sebagai metode yang bisa di aplikasikan lebih luas serta kemudahan dalam penggunaan. Sehingga, dari kelebihan kegunaan kedua metode tersebut diharapkan mampu memberikan solusi untuk mengurangi kecelakaan kerja di perusahaan PT. X khususnya pada proyek pembuatan drainase.

\section{METODE PENELITIAN}

Tahap-tahap pengumpulan data dengan cara wawancara serta kuesioner dengan tahap pertama yaitu studi pendahuluan dan studi literatur dengan cara observasi langsung pada bagian pembuatan drainase disetiap bagian pekerjaan seperti pada tahap persiapan, pemotongan, perakitan, pengecoran, serta tahap akhir yaitu pemasangan untuk 
mengetahui beberapa permasalahan pada PT. X yang kemudian akan menjadi topik pembahasan pada penelitian ini.

Rumusan masalah pada penelitian ini yaitu untuk mengetahui apa saja risiko kecelakaan kerja yang disebabkan oleh human error, berapa nilai probabilitas human error yang terjadi dan cara mengurangi atau rekomendasi untuk human error yang ada pada setiap sub pekerjaan.

Tujuan penelitian ini adalah mengurangi nilai probabilitas human error yang terjadi serta memberikan rekomendasi untuk human error yang terjadi pada pekerjaan drainase serta membandingkan nilai HEP metode HEART dan SPAR-H. Data primer yang diperlukan pada penelitian ini yaitu berupa data proses pembuatan drainase, data kecelakaan kerja serta human error yang pernah terjadi, data EPC, data generic task, data POA serta PSF's, sedangkan data sekunder yang diperlukan adalah studi literatur atau jurnal penelitian terdahulu.

Tahap pengolahan data terbagi menjadi 2 yaitu pengolahan data dengan menggunakan metode HEART dan pegolahan data dengan menggunakan metode SPAR-H, sebagai berikut:

1. Tahap pengolahan data dimulai dengan pengelompokkan sub-sub pekerjaan menggunakan Hierarchical Task Analysis (HTA), kemudian selanjutnya melakukan pengukuran reliabilitas untuk masing-masing sub pekerjaan dengan penilaian dari penilaian tabel EPC, Generic task, serta POA.

2. Pengolahan data dengan menggunakan metode SPAR-H juga dilakukan dengan menganalisa subsub pekerjaan yang sudah diolah dengan HTA, kemudian melakukan penilaian sub-sub pekerjaan dengan menghitung nilai diagnosis failure probabilities 0,01 dan 0,001 untuk pekerjaan action, kemudian menentukan besar bobot kesalahan untuk faktor waktu (time), stress, tingkat kesulitan (complexity), pengalaman kerja (experience), prosedur kerja, ergonomi, kesehatan pekerja (fitness for duty), serta prosesor.

\section{HASIL DAN PEMBAHASAN}

Proses pembuatan drainase melalui 5 tahap yaitu persiapan, pengukuran dan pemotongan, perakitan, pengecoran, serta pemasangan. Tahap-tahap tersebut kemudian dikelompokkan menggunakan Hierarchical Task Analysis yang dapat dilihat pada Gambar 1.

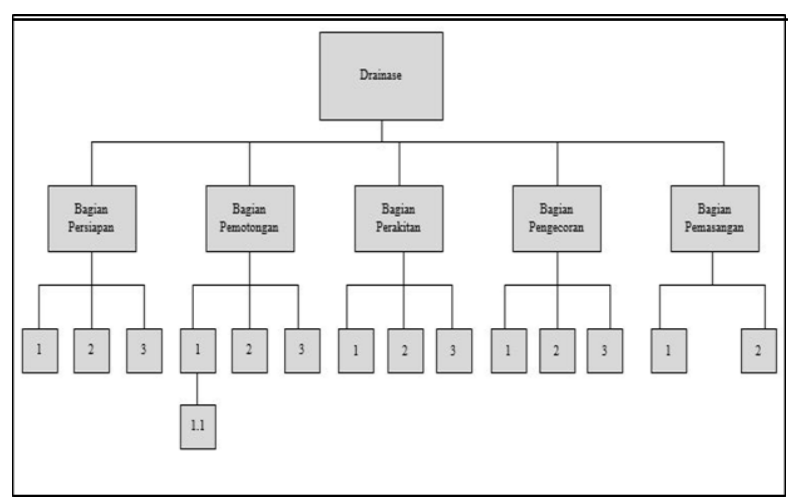

Gambar 1. Hierarchical Task Analysis Drainase

Setelah mengetahui sub-sub pekerjaan dari setiap pekerjaan utama maka dilakukan perhitungan dengan metode HEART untuk mengetahui nilai HEP, dengan menentukan nilai Assessed Effect dengan contoh perhitungan pada task persiapan pada bagian pengambilan raw material sebagai berikut: 
1. Task pengambilan raw material dari penerimaan $\left(\mathrm{EPC}_{33}{ }_{33}\right)$

$\mathrm{AE}=((1,15-1) \times 0,3))+1$

$\mathrm{AE}=1,045$

2. Task pengambilan raw material dari penerimaan $\left(\mathrm{EPC}_{23}{ }_{23}\right)$

$\mathrm{AE}=((1,6-1) \times 0,3))+1$

$\mathrm{AE}=1,18$

Setelah diketahui nilai assessed effect pada task pengambilan raw material dari penerimaan dengan masing-masing EPC, maka selanjutnya adalah melakukan perhitungan HEP. Berikut ini merupakan contoh perhitungan HEP pada task pengambilan raw material:

$$
\begin{aligned}
& \mathrm{HEP}=(\mathrm{AE} 1 \times \mathrm{AE} 2 \times 0,003) \\
& \mathrm{HEP}=(1,045 \times 1,18 \times 0,003) \\
& \mathrm{HEP}=0,0036
\end{aligned}
$$

Selanjutnya menghitung nilai HEP dengan menggunakan metode SPAR-H, langkah pertama yang dilakukan adalah untuk mendapatkan nilai PSF Composite, sebagai contoh perhitungan pada task pengambilan raw material berikut:

PSFComposite $_{\text {action }}=0,001 \times 0,1 \times 1 \times 1 \times 1$

$$
\times 1 \times 10 \times 1 \times 2
$$

PSFComposite $_{\text {action }}=2$

Setelah mengetahui nilai PSF composite maka dilakukan tahap perhitungan untuk mendapatkan nilai HEP dengan contoh pada bagian pengambilan raw material sebagai berikut:

$$
\begin{aligned}
\text { HEP } & =\frac{0,001 \times 2}{0,001 \times(2-1)+1} \\
& =0,0019
\end{aligned}
$$

Setelah melakukan tahap untuk mengetahui nilai HEP pada masingmasing metode maka nilai-nilai tersebut dimasukkan pada Fault Tree Analysis untuk mengetahui pola kegagalan dengan menghubungkan hasil identifikasi kecelakaan kerja dengan hasil reliabilitas pada setiap bagian pekerjaan yang ada pada proses pembuatan drainase. Fault Tree Analysis ini akan diolah menjadi dua yang pertama yaitu dari hasil perhitungan dengan menggunakan metode HEART yang dapat dilihat pada Gambar 2 dan untuk hasil perhitungan dengan metode SPAR-H yang dapat dilihat pada Gambar 3.

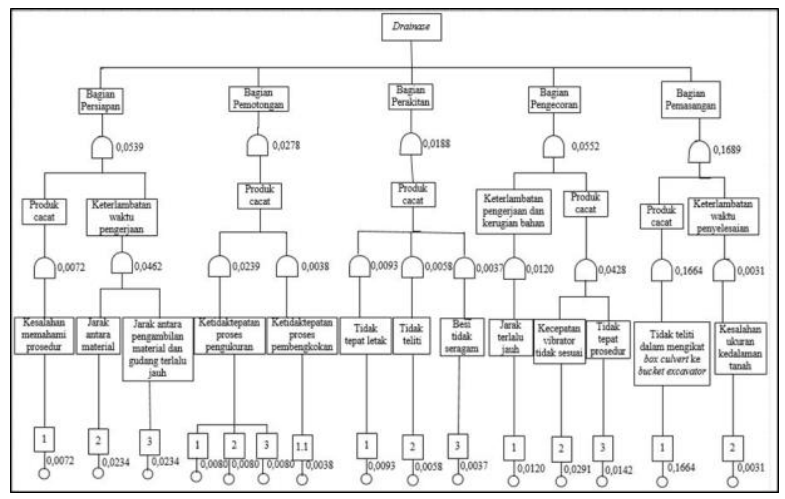

Gambar 2. Pola Kesalahan Hasil Metode HEART

Dari gambar diatas, diketahui bahwa nilai probabilitas terjadinya human error terbesar yaitu pada bagian pemasangan dengan nilai HEP total sebesar 16,89\%, sub pekerjaan yang menjadi pendorong terbesar terjadinya human error berada pada sub pekerjaan pemindahan box culvert ke bagian pemasangan dengan nilai $16,64 \%$. Adapun untuk faktor terjadinya human error berupa produk cacat yaitu dikarenakan ketidaktelitian pada proses pengikatan box culvert ke bagian bucket excavator, sedangkan untuk pekerjaan yang memiliki nilai HEP keseluruhan tertinggi kedua adalah pada bagian pekerjaan pengecoran dengan nilai HEP keseluruhan sebesar 5,52\% dengan nilai human error yang menjadi faktor pendukung terbesar terjadinya human error untuk bagian pengecoran adalah pada sub pekerjaan pengoperasian beton 
vibrator dan pelepasan rangka bekisting yang menyebabkan produk cacat dengan nilai HEP sebesar 4,28\%, selanjutnya untuk nilai HEP keseluruhan terbesar ketiga adalah pada bagian persiapan yaitu dengan nilai total sebesar 5,39\% dan nilai human error terbesar yang menjadi faktor pendukung adalah pada sub pekerjaan pengambilan raw material dan penyusunan raw material sebesar 4,62\% dengan kemungkinan terjadinya human error yaitu keterlambatan waktu pengerjaan yang disebabkan oleh jarak antara material dan jarak pengambilan material ke gudang terlalu jauh, selanjutnya yaitu pada bagian pemotongan HEP sebesar 2,78\% yang menjadi faktor pendukung utama terjadinya human error pada bagian ini berada pada sub pekerjaan pengukuran dan pemotongan besi, kayu serta kawat dengan nilai HEP sebesar 2,39\%, yang menjadi faktor kesalahan sehingga menyebabkan produk cacat adalah dikarenakan terjadinya ketidaktepatan proses pengukuran. Sedangkan untuk nilai HEP terkecil berada pada bagian pekerjaan perakitan dengan nilai HEP sebesar 1,88\% dengan nilai human error terbesar pada sub pekerjaan pemasangan kayu pada dinding dan lantai bekisting sebesar 0,93\% yang dikarenakan tidak tepat letak pemasangan kayu sehingga mengakibatkan produk cacat.

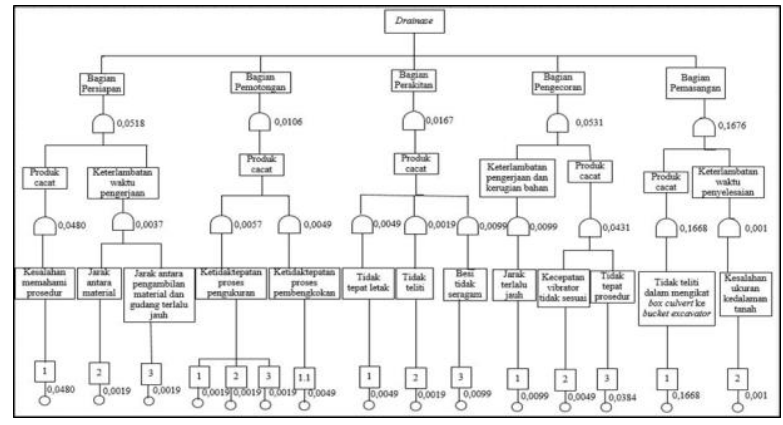

Gambar 3. Pola Kesalahan Hasil Metode SPAR-H
Pada gambar diatas, dapat diketahui bahwa probabilitas atau kemungkinan terjadinya human error pada setiap bagian pekerjaan dari tahap persiapan hingga pemasangan. Untuk nilai human error terbesar berada pada bagian pemasangan yaitu sebesar $16,76 \%$ dengan kemungkinan jenis human error yang menjadi faktor terbesar yaitu produk cacat yang disebabkan oleh ketidaktelitian dalam proses mengikat tali dari box culvert ke bucket excavator sehingga menimbulkan kemungkinan box culvert terjatuh pada sub pekerjaan pemindahan box culvert dari gudang ke lokasi pemasangan yaitu sebesar 16,68\%, selanjutnya untuk nilai human error tertinggi kedua yaitu sebesar 5,31\% pada bagian pengecoran yang mana pada bagian ini nilai terbesar berada pada $s u b$ pekerjaan 2 dan 3 yang menyebabkan produk cacat dikarenakan kecepatan beton vibrator yang tidak sesuai pada saat $s u b$ pengoperasian beton vibrator serta prosedur yang tidak tepat pada sub pekerjaan pelepasan rangka bekisting dengan nilai 4,31\%, selanjutnya nilai human error terbesar ketiga yaitu pada sub pekerjaan persiapan yaitu sebesar 5,18\% dengan kemungkinan human error terbesar berupa produk cacat yang disebabkan oleh kesalahan dalam memahami prosedur pada bagian sub pekerjaan memahami prosedur pembuatan box culvert dengan nilai sebesar 4,80\%, nilai human error terbesar selanjutnya yaitu pada bagian perakitan yaitu sebesar 1,67\% nilai human error terbesar berada pada sub pekerjaan pemasangan besi pada rangka bekisting yang disebabkan oleh ukuran dan jenis besi yang tidak seragam dengan nilai sebesar $0,99 \%$, selanjutnya pada bagian 
pemotongan memiliki nilai human error probability sebesar $1,06 \%$ dengan jenis human error terbesar yaitu ketidaktepatan proses pengukuran yang terjadi pada sub pekerjaan pengukuran dan pemotongan besi, kayu serta kawat yang memiliki nilai sebesar $0,57 \%$. Setelah mengetahui nilainilai serta sub pekerjaan yang mengakibatkan human error terbesar maka tahap selanjutnya membandingkan hasil nilai HEP dari kedua metode HEART dan SPAR-H dalam bentuk grafik pada Gambar 4.

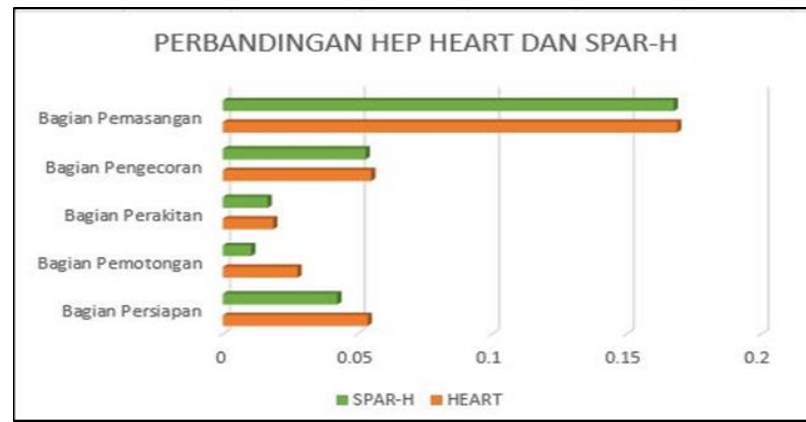

Gambar 4. Grafik Perbandingan HEP HEART dan SPAR-H

Dari grafik diatas dapat diketahui bahwa nilai HEP dengan menggunakan metode HEART lebih besar dibandingkan dengan menggunakan metode SPAR-H, namun besar nilai HEP antar kedua metode tidak terlalu spesifik dan relatif sama dikarenakan seluruh beberapa faktor pada kedua metode dipilih sesuai dengan kejadian atau faktor pendukung terjadinya human error di lapangan, adapun besarnya nilai HEP dengan metode HEART dipengaruhi oleh penilaian expert pada generic task type dan EPC, terdapat 5 jenis kategori pada generic task type yang diperoleh untuk perhitungan menggunakan metode HEART ini yaitu kategori C, E, F, A dan G untuk msingmasing sub pekerjaan dalam bagian pekerjaan tersebut dengan nilai yang jauh lebih tiggi jika dibandingkan dengan penilaian pada SPAR-H yang hanya menggunakan tabel PSF saja. Selain dari pengaruh nilai generic task type terdapat pula pengaruh penilaian dari tabel EPC untuk setiap sub-sub pekerjaan dari keempat pekerjaan tersebut, terdapat 33 jenis EPC keseluruhan yang digunakan untuk beberapa sub pekerjaan yang ada pada bagian pemotongan, perakitan, pengecoran serta pemasangan dengan nilai yang cukup besar sedangkan penilaian untuk PSF pada metode SPAR-H hanya berkisar dari nilai 1-10. Berdasarkan hasil dari identifikasi faktorfaktor yang menyebabkan terjadinya human error maka diketahui beberapa hal yang dapat menyebabkan kecelakaan kerja yaitu sebagai berikut.

1. Pekerja yang berada pada daerah pemasangan tali ke bucket excavator tertimpa box culvert,

2. Error pada operator dalam mengendalikan excavator dikarenakan jam istirahat yang kurang,

3. Bucket excavator terkena pengguna jalan yang melewati lokasi pemasangan,

4. Box culvert menimpa pekerja pada lokasi galian saat pelepasan pengikat box culvert pada bucket excavator

Berdasarkan hasil identifikasi kemungkinan jenis kecelakaan kerja yang terjadi serta hasil perhitungan human error yang dilakukan dengan menggunakan metode HEART dan SPAR-H maka berikut ini merupakan analisa atau rekomendasi pengurangan human error dengan pendekatan K3 dan Ergonomi sesuai dengan identifikasi pada langkah perhitungan sebelumnya. 
1. Dapat diketahui pada hasil perhitungan HEP dengan menggunakan metode HEART dan SPAR-H, human error pada bagian pemasangan dipengaruhi oleh waktu kerja yang berlebihan serta tidak terdapat waktu untuk melatih pikiran dan tubuh diluar waktu kerja sehingga menyebabkan kesehatan fisik maupun mental operator menurun, hal ini menyebabkan penurunan performansi pekerja dalam menyelesaikan pekerjaan dengan baik, sehingga hal yang harus dilakukan perusahaan adalah memberikan waktu istirahat yang cukup bagi pekerja, tidak menambah waktu kerja yang telah ditetapkan, memberikan penambahan pekerja pada bagian operator excavator agar dapat dilakukan dengan cara penganturan shift pada pekerjaan siang dan malam serta melakukan pengecekan rutin terhadap kesehatan pekerja,

2. Kurangnya kualitas informasi juga menjadi faktor yang menyebabkan human error terjadi sehingga menyebabkan produk cacat, selain itu dapat menyebabkan bahaya antar pekerja dan pengguna jalan lainnya. Maka yang harus dilakukan oleh perusahaan dalam menangani hal ini adalah dengan memberikan informasi yang jelas mengenai proses pemindahan box culvert berupa urutan-urutan pekerjaan yang dilakukan serta menambah rambu-rambu peringatan pada jalur yang dilewati oleh excavator agar pekerja pada sekitar lintasan excavator dapat berhati-hati serta mengetahui arah jalannya excavator tersebut.

\section{KESIMPULAN}

Berdasarkan hasil dari pengolahan, analisa serta tujuan penelitian, berikut ini merupakan kesimpulan yang diperoleh, yaitu:

1. Dari hasil identifikasi pekerjaan, diketahui bahwa terdapat 15 bagian pekerjaan yang ada pada proyek pembuatan drainase di jalan Wahid Hasyim, dengan masing-masing risiko yang terjadi serta jenis human error pada beberapa bagian pekerjaan seperti produk cacat serta keterlambatan penyelesaian pekerjaan, dengan penyebab yang diketahui melalui identifikasi seperti ketidaktelitian dalam pengukuran, jarak yang terlalu jauh, ketidaktelitian dalam pemasangan dan pemilihan bahan serta identifikasi faktor-faktor lainnya dengan menggunakan tabel generic task analysis, error producing conditions pada metode HEART dan tabel PSF's pada metode SPAR-H.

2. Nilai human error probability untuk setiap bagian pekerjaan dengan menggunakan metode HEART pada bagian persiapan sebesar 5,39\%, bagian pemotongan dan perakitan seesar 2,78\% dan $1,88 \%$ serta pada bagian pengecoran sebesar 5,52\% dan pada bagian pemasangan sebesar $16,89 \%$ sedangkan dengan menggunakan metode SPAR-H diperoleh nilai HEP pada bagian persiapan sebesar $4,26 \%$, pada bagian pemotongan sebesar $1,06 \%$, bagian perakitan sebesar $1,67 \%$ dan pada bagian pengecoran sebesar 5,31\% serta pada bagian pemasangan sebesar 16,76\%.

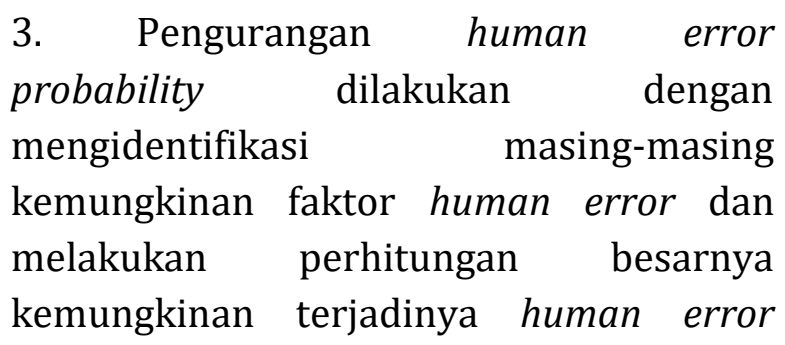


Tita Dwi Riyanti, Willy Tambunan dan Yudi Sukmono. Analisis Human Reliability Assessment (HRA) dengan Metode HEART dan SPAR-H (Studi Kasus PT.X).

pada setiap pekerjaan yang ada sehingga dapat menimbulkan kemungkinan kecelakaan kerja, pengurangan ini dilakukan dengan menggunakan pendekatan K3 dan ergonomic pada tahap pekerjaan yang memiliki HEP terbesar yaitu pada tahap pemindahan box culvert dari gudang ke lokasi pemasangan dengan rekomendasi pengurangan yaitu memberikan waktu istirahat yang cukup, tidak menambah waktu kerja diluar waktu yang telah ditentukan, memberikan tambahan pekerja sebagai operator excavator agar shift kerja dapat dilakukan pada siang dan malam, memberikan walkie talkie sebagai alat bantu operator berkomunikasi dengan pekerja yang mengatur jalur pada saat pengoperasian excavator, memberikan tanda peringatan pada saat excavator beroperasi agar pengguna jalan lainnya lebih berhati-hati serta melakukan penimbunan tanah pada bagian tanah yang tidak rata sehingga dapat mempersulit jalannya excavator.

\section{DAFTAR PUSTAKA}

Annett, John., (2003). Hierarchical Task Analysis, Handbook of Cognitive Task Design, University of Warwick, United Kingdom.

Ansori, N., \& Mustajib, I., (2013). Sistem Perawatan Terpadu, Graha Ilmu, Yogyakarta.

Bell, Julie., \& Holroyd, J., (2009). Review of Human Reliability Assessment Methods, Health and Safety Laboratory, Buxton.

Christina, Wieke Yuni., Djakfar, L., Thoyib., A., (2012). Pengaruh Budaya Keselamatan dan Kesehatan Kerja (K3) Terhadap Kinerja Proyek Kontruksi, Jurnal Rekayasa Sipil, Vol.6, No.1, ISSN: 1978-5658, Universitas Brawijaya Malang.

Dhillon, B, S., (2005). Reliability, Quality and Safety for Engineers, CRC Pess, Bocca Raton Florida.
Fairizi, Dimitri., (2015). Analisis dan Evaluasi Saluran Drainase Pada Kawasan Prumnas Talang Kelapa di Subdas Lambidaro Kota Palembang, Jurnal Teknik Sipil, Vol.3, No.1, ISSN: 2355-374X, Universitas Sriwijaya.

Guspara, W, Adhitia., Sadwikasanti, T., Jian, L., (2018). Hierarchical Task Analysis Dalam Pengembangan Gagasan Produk, Jurnal Desain Produk (Pengetahuan dan Perancangan Produk), Vol.3, No.4, ISSN: 2579-7328 (online), ISSN:2477-7900 (Printed), Universtitas Kristen Duta Wacana, Yogyakarta.

Rohmawan, F., Dian, Palupi, R., (2016). Penggunaan Metode HEART dan JSA Sebagai Upaya Pengurangan Human Error Pada Kecelakaan Kerja di Departemen Produksi, Jurnal Teknik Industri, Vol.17, No.1, ISSN:1978-1431 (print), ISSN: 2527-4112 (online),Universitas Muhammadiyah Malang.

Suma'mur, P.K., (2009). Higiene Perusahaan dan Kesehatan Kerja (HIPERKES), Jakarta.

Safitri, Dian Mardi., Ayu, RA., Nataya, CR., (2015). Human Reliabillity Assesment dengan Metode Human Eror Assessment dan Reduction Technique Pada Operator Stasiun Shroud PT.X, Jurnal Rekayasa Sistem Industri, Universitas Trisakti, Jakarta.

Gertman., et al., (2005). The Spar-H Human Reliability Analysis Method, Idaho International Laboratory, Washington DC.

Iridiastadi, hardianto., Yassierli., (2014). Ergonomi Suatu Pengantar, Rosda Jaya Putra.

Lukitosari, Y, A., Handoko, L., Amrullah, H, A., (2018). Aanalisa Probabilitas Human Error Pekerja Sandblastic dengan Mengunakan Metode SPAR-H, ISSN: 2581-2653, Politeknik Perkapalan Negeri Surabaya.

Chalis Fajri Hasibuan, Yudi Daeng P, Reza Rinaldi Hasibuan. 2020. Human Reliability Assessment Analysis with Human Error Assessment and Reduction Technique (HEART) Method on Sterilizer Station at XYZ Company. IOP Conference Series: Materials Science and Engineering. $851: 1-7$. 